\title{
A basic application of mathematical tool to market prices
}

\author{
Lijiang Zeng \\ Research Centre of Zunyi Normal College \\ Zunyi 563099, Guizhou, China \\ zlj4383@sina.com
}

Abstract--In the real life, the financial market plays important roll to our all kinds of business. And the market prices can cause very great social problems. So, it has important significance to research the markets prices, in this paper, we show that use mathematics as tools to research the markets prices, and obtained very interesting conclusion.

Keywords-financial market; prices of market; mathematics; demand

\section{INTRODUCTION}

In the real life, the financial market ${ }^{[1-6]}$ plays important roll to our all kinds of business ${ }^{[7-9]}$, and the market prices ${ }^{[10]}$ can cause very great social problems. In real markets, they supply and demand determine nonequilibrium prices ${ }^{[11]}$. There are bid prices by prospective buyers ${ }^{12]}$ and ask prices by prospective sellers ${ }^{[13]}$, so by "price" we mean here the price at which the last trade occurred. This is not a clear definition for a slow-moving, illiquid market like housing, but is well-enough defined for trades of [14], or a currency like the [15].

\section{BeginNing From A ReAl ExAmple}

Lt's beginning from following example. The simplest case for continuous time trading, an idealization of limited validity, would be an equation of the form

$$
\frac{d p}{d t}=D(p, t)-S(p, t)=\varepsilon(p, t)
$$

where $p_{k}$ is the price of an item like a computer or a cup of coffee, $D$ is the demand at price $p, S$ is the corresponding supply and the vector field $\varepsilon$ is the excess demand ${ }^{[16]}$. Phase space is just the $n$-dimensional $p$-space, and is flat with no metric. More generally, we could assume that $\frac{d p}{d t}=f(\varepsilon(p, t))$, where $f$ is any vector field with the same qualitative properties as the excess demand. Whatever the choice, we must be satisfied with studying topological classes of excess demand functions, because the excess demand function cannot be uniquely specified by the theory. Given a model, equilibrium is determined by vanishing excess demand, by $\varepsilon=0$. Stability of equilibrium, when equilibria exist at all, is determined by the behavior of solutions displaced slightly from an equilibrium point. Note that dynamics requires only that we specify $x=D(p)$, not $p=f(x)$, and likewise for the supply schedule. The empirical and theoretical importance of this fact will become apparent below.

We must also specify a supply function $x=S(p)$. If we assume that the production time is long on the time scale for trading then we can take the production function to be constant, the "initial endowment," $S(p) \approx x_{0}$, which is just the total supply at the initial time to. This is normally assumed in papers on neo-classical equilibrium theory. In this picture agents simply trade what is available at time $t=0$, there is no new production (pure barter economy).

With demand assumed slaved to price in the form $x=D(p)$, the phase space is the $n$-dimensional space ${ }^{[17]}$ of the prices $p$. That phase space is flat means that global parallelization of flows is possible for integrable systems. The $n$-component ordinary differential equation (1) is then analyzed qualitatively in phase space by standard methods. In general there are $n-1$ time-independent locally conserved quantities, but we can use the budget constraint to show that one of these conservation laws is global: if we form the scalar product of $p$ with excess demand $\varepsilon$ then applying the budget constraint to both $D$ and $S$ yields

$$
p \varepsilon(p)=0
$$

The underlying reason for this constraint, called Walras's Law, is that capital and capital accumulation are not allowed in neo-classical theory: neo-classical models assume a pure barter economy, so that the cost of the goods demanded can only equal the cost of the goods offered for sale. This condition means simply that the motion in the $n$-dimensional price space is confined to the surface of an $n$-1-imensional sphere. Therefore, the motion is at most $n$-1-dimensional. What the motion looks like on this hypersphere for $n>3$ is a question that cannot be answered a priori without specifying a definite class of models. Hyperspheres in dimensions $n=3$ and 7 are flat with torsion, which is nonintuitive. Given a model of excess demand we can start by analyzing the number and character of equilibria and their stability. Beyond that, one can ask whether the motion is integrable. Typically, the motion for $n>3$ is nonintegrable and may be chaotic or even complex, depending upon the topological class of model considered.

\section{AN EXAMPLE Of EXPECtation Of StABle EQUILIBRIUM}

As an example of how easy it is to violate the expectation of stable equilibrium within the confines of optimizing behavior, we present next the details of H. Scarf's model ${ }^{[18]}$. In 
that model consider three agents with three assets. The model is defined by assuming individual utilities of the form

$$
U_{i}(x)=\min \left(x_{1}, x_{2}\right)
$$

and an initial endowment for agent number 1

$$
x_{0}=(1,0,0)
$$

The utilities and endowments of the other two agents are cyclic permutations on the above. Agent $k$ has one item of asset $\mathrm{k}$ to sell and none of the other two assets. Recall that in neo-classical theory the excess demand equation (1) is interpreted only as a price-adjustment process, with no trades taking place away from equilibrium. If equilibrium is reached then the trading can only be cyclic with each agent selling his asset and buying one asset from one of the other two agents: either agent 1 sells to agent 2 who sells to agent 3 who sells to agent l, or else agent $l$ sells to agent 3 who sells to agent 2 who sells to agent 1 . Nothing else is possible at equilibrium. Remember that if equilibrium is not reached then, in this picture, no trades occur. Also, the budget constraint, which is agent $k$ 's income from selling his single unit of asset $k$ if the market clears (he or she has no other source of income other than from what he or she sells), is

$$
M=\tilde{p} x_{0}=p_{k}
$$

Because cyclic trading of a single asset is required, one can anticipate that equilibrium can be possible only if $p_{1}=p_{2}=p_{3}$, In order to prove this, we need the idea of "indifference curves."

The idea of indifference curves in utility theory, discussed by [19], may have arisen in analogy with either thermodynamics or potential theory. Indifference surfaces are defined in the following way. Let $U\left(x_{1}, \cdots, x_{n}\right)=C=$ constant. If the implicit function theorem is satisfied then we can solve to find one of the $x$ s, say $x_{i}$, as a function of the other $n-1 x$ s and $C$. If we hold all $x$ s in the argument of $\mathrm{f}$ constant but one, say $x_{j}$, then we get an "indifference curve"

$$
x_{i}=f\left(x_{j}, C\right)
$$

We can move along this curve without changing the utility $U$ for our "rational preferences." This idea will be applied in an example below.

The indifference curves for agent I are as follows. Note first that if $x_{2}>x_{1}$ then $x_{1}=C$ whereas if $x_{2}<x_{1}$ then $x_{2}=C$. Graphing these results yields as indifference curves $x_{2}=f\left(x_{1}\right)=x_{1}$. Note also that $p_{3}$ is constant. Substituting the indifference curves into the budget constraint yields the demand vector components for agent $l$ as

$$
x_{1}=\frac{M}{p_{1}+p_{2}}=D_{1}(p) \quad x_{2}=\frac{M}{p_{1}+p_{2}}=D_{2} \quad(p) x_{3}=0
$$

The excess demand for agent $\mathrm{I}$ is therefore given by

$$
\varepsilon_{11}=\frac{p_{1}}{p_{1}+p_{2}}-1=\frac{p_{2}}{p_{1}+p_{2}} \quad \varepsilon_{12}=\frac{p_{1}}{p_{1}+p_{2}} \quad \varepsilon_{13}=0
$$

where $\varepsilon_{i j}$ is the $j$ th component of agent $i$ 's excess demand vector. We obtain the excess demands for agents 2 and 3 by cyclic permutation of indices. The $k$ th component of total excess demand for asset $k$ is given by summing over agents

so that

$$
\varepsilon_{k}=\varepsilon_{1 k}+\varepsilon_{2 k}+\varepsilon_{3 k}
$$

$$
\begin{aligned}
& \varepsilon_{1}=\frac{-p_{2}}{p_{1}+p_{2}}+\frac{p_{3}}{p_{1}+p_{3}} \\
& \varepsilon_{2}=\frac{-p_{3}}{p_{2}+p_{3}}+\frac{p_{1}}{p_{1}+p_{2}} \\
& \varepsilon_{3}=\frac{-p_{1}}{p_{3}+p_{1}}+\frac{p_{2}}{p_{2}+p_{3}}
\end{aligned}
$$

The excess demand has a symmetry that reminds us of rotations on the sphere. In equilibrium $\varepsilon=0$ so that

$$
p_{1}=p_{2}=p_{3}
$$

is the only equilibrium point. It is easy to see that there is a second global conservation law

$$
p_{1} p_{2} p_{3}=C_{2}
$$

following from

$$
\varepsilon_{1} p_{3}+\varepsilon_{2} p_{1} p_{3}+\varepsilon_{3} p_{1} p_{2}=0
$$

With two global conservation laws the motion on the 3 -sphere is globally integrable, chaotic motion is impossible.

It is now easy to see that there are initial data on the 3 -sphere from which equilibrium cannot be reached. For example, let

$$
\left(p_{10}, p_{20}, p_{30}\right)=(1,1,1)
$$

so that

$$
p_{1}^{2}+p_{2}^{2}+p_{31}^{2}=3
$$

Then with $p_{10} p_{20} p_{30}=1$ equilibrium occurs but for other initial data the plane is not tangent to the sphere at equilibrium and equilibrium can not be reached. The equilibrium point is an unstable focus enclosed by a stable limit cycle. In general, the market oscillates and cannot reach equilibrium. For four or more assets it is easy to write down models of excess demand for which the motion is chaotic.

\section{THE NEO-ClAssicAl THEORY}

The neo-classical theorist Roy Radner ${ }^{[20]}$ arrived at a much stronger criticism of the neo-classical theory from within. Suppose that agents have slightly different information initially. Then equilibrium is not computable. That is, the information demands made on agents are so great that they cannot locate equilibrium. In other words, maximum computational complexity enters when we deviate even slightly from the idealized case. It is significant that if agents cannot find an equilibrium point, then they cannot agree on a price that will 
clear the market. This is one step closer to the truth: real markets are not approximated by the neo-classical equilibrium model. Radner also points out that liquidity demand, the demand for cash as savings, for example, arises from two basic sources. First, in a certain but still neo-classical world liquidity demand would arise because agents cannot compute equilibrium, cannot locate it. Second, the demand for liquidity arises from uncertainty about the future. The notion that liquidity reflects uncertainty will appear when we study the dynamics of financial markets.

In neo-classical equilibrium theory, perfect information about the infinite future is required and assumed. In reality, information acquired at one time is incomplete and tends to become degraded as time goes on. Entropy change plays no role in neo-classical economic theory in spite of the fact that, given a probability distribution reflecting the uncertainty of events in a system of the market, [21] entropy describes both the accumulation and degradation of information. Neo-classical theory makes extreme demands on the ability of agents to gather and process information but, as [22] wrote, it is extremely difficult in practice to know what is noise and what is information. For example, when one reads the financial news one usually only reads someone else's opinion, or assertions based on assumptions that the future will be more or less like the past. Most of the time, what we think is information is probably more like noise or misinformation. This point of view is closer to finance theory, which does not use neo-classical economics as a starting point.

\section{ANOTHER IMPORTANT POINT ABOUT INFORMATION}

Another important point is that information should not be confused with knowledge [23]. The symbol string "saht" (based on at least a 26 letter alphabet a-z) has four digits of information, but without a rule to interpret it the string has no meaning, no knowledge content. In English we can give meaning to the combinations "hast," "hats," and "shat." Information theory is based on the entropy of all possible strings that one can make from a given number of symbols, that number being $4 !=24$ in this example, but "information" in standard economics and finance theory does not make use of entropy.

Neo-classical economic theory assumes $100 \%$ efficiency, it perfect matching a buyer to every seller, and vice versa, but typical markets outside the financial ones are highly illiquid and inefficient (housing, automobiles. floorlamps, carpets, etc.) where it is typically relatively hard to match buyers to sellers. Were it easy to match buyers to sellers, then advertising and inventory would be largely superfluous. Seen from this standpoint, one might conclude that advertising may distort markets instead of making them more efficient.

\section{ACKNOWLEDGMENTS}

This work was supported by Natural Science Foundation (13116339) of China; Natural Science Foundation ([2015]2067) of Science and Technology Department of Guizhou; Natural Science Foundation([2015]722) of Education Department of Guizhou; Hundred of talents project(2015) of Zunyi Normal College.

\section{REFERENCE}

[1] Clarke, George, Xu, Lixin Colin, and Zou, Heng-fu. Finance and Income Inequality: Test of Alternative Theories[C]. World Bank Policy Research Working Paper, 2003, 2984

[2] Beck, Thorsten, B Asli Demirguc, Kunt, and Ross Levine. Finance Inequality and Poverty: Cross-Country Evidence[J]. World Bank Policy Research Working Paper, 2004(2) . 3338-3342

[3] Blank, B, Gilson, R. Venture Capital and the Structure of Capital Markets: Blanks Versus Stock Markets[J]. The Journal of Finance. 1998(3), 89-92

[4] Henderson J V. The effects of urban concentration on economic growth[J]. NBER Working Paper, 2000(3), 7503-7506

[5] Iyigun, Ann. Income Inequality, Financial Development and Macroeconomic Fluctuations[J]. The Economic Journal . 2004(2), 56-61

[6] Beck, Thorsten, Asli Demirguc-Kunt, and Ross Levine. Finance, Inequality and Poverty: Cross-Country Evidence. World Bank Policy Research Working Paper[C]. 2004, 3338

[7] Levine, Ross. Financial intermediation and growth: Causality and causes[J]. Journal of Monetary Economics. 2000(3), 46-50

[8] Blank, B, Gilson, R. Venture Capital and the Structure of Capital Markets: Blanks Versus Stock Markets[J]. The Journal of Finance. 1998(4),82-87

[9] Nenova Tatiana. The value of corporate voting rights and control: a cross-country analysis[J]. The Journal of Finance. 2003(3),90-93

[10] Steven N Kaplan, and Per Stromberg. Financial Contracting Theory Meets the Real World: An Empirical Analysis of Venture Capital Contracts[J]. the review of economic studies. 2003(2),68-71

[11] C. Casamatta. Financing and advising: Optimal financial contracts with venture capitalists[J]. The Journal of Finance. 2003(2),86-90

[12] Mc Quaid, R. W., Greig, M., Adams, J. Are New Deal employment initiatives on target Evidence from job search success in local labor markets[J]. International Journal of Manpower . 2004(2), 78-82

[13] Barclay M J, Holderness C G. Private benefits from control of public corporations[J]. The Journal of Finance . 1989(1),78-81

[14] Akerlof. The Market for "Lemons": Qualitative Uncertainty and The Market Mechanism Quarterly[J]. Journal of Applied Economics. 1970(2),102-105

[15] S. Barrios, L. Bertinelli, E. Strobl, AC Teixeira. Agglomeration Economies and the Location of Industries: A Comparison of Three Small European counties[J]. CORE Discussion Paper . 2003(3),67-70

[16] Anneleen Forrier, Luc Sels. The concept employability: a complex mosaic[J]. Int. J. Human Resources Development and Management . 2003, 143-148

[17] Hardy R L. Theory and applications of the multi-quadric biharmonic method[C]. Computers and Mathematics With Applications. 1990,123-129

[18] Xinping Xiao, Yichen Hu, Huan Guo. Modeling mechanism and extension of GM $(1,1)[\mathrm{J}]$. Journal of Systems Engineering and Electronics. 2013(03), 65-68

[19] Kai Diethelm,Guido Walz. Numerical solution of fractional order differential equations by extrapolation[J]. Numerical Algorithms . 1997 (3-4), 67-71

[20] Mel Fugate, Angelo J. Kinicki, Blake E. Ashforth. Employ ability: A psychosocial construct, its dimensions, and applications[J]. Journal of Vocational Behavior . 2004(2), 88-92

[21] Lindsay, C., Mcquaid, R. W. Avoiding the 'McJobs': unemployed job seekers and attitudes to service work. Work[J], Employment and Society . 2004(1), 88-93

[22] Clarke, George, Xu, Lixin Colin, and Zou, Heng-fu. Finance and Income Inequality: Test of Alternative Theories r[J]. World Bank Policy Research Working Pape. 2003(1), 2984 -2989.

[23] REN HuiLan ,MA TianBao, YAO XiaoHu. Numerical studies of penetration problems by an improved particle method[J]. Science China(Physics,Mechanics \& Astronomy). 2012(12), 43-47 